\title{
The Brazilian version of STarT Back Screening Tool - translation, cross-cultural adaptation and reliability*
}

\author{
Bruna Pilz ${ }^{1,2}$, Rodrigo A. Vasconcelos ${ }^{1,2}$, Freddy B. Marcondes ${ }^{1,3}$, \\ Samuel S. Lodovichi ${ }^{4}$, Wilson Mello ${ }^{1}$, Débora B. Grossi ${ }^{2}$
}

\begin{abstract}
Background: Psychosocial factors are not routinely identified in physical therapy assessments, although they can influence the prognosis of patients with low back pain. The "STarT Back Screening Tool" (SBST) questionnaire aids in screening such patients for poor prognosis in the primary care setting and classifies them as high, medium, or low risk based on physical and psychosocial factors. Objectives: This study sought to translate and cross-culturally adapt the SBST to the Brazilian Portuguese language and test the reliability of the Brazilian version. Method: The first stage of the study consisted of the translation, synthesis, and back-translation of the original version of the STSB, including revision by the Translation Group, pretest of the translated version, and assessment by an expert panel. The pre-final Brazilian version was applied to 2 samples comprising 52 patients with low back pain; these patients were of both genders and older than 18 years of age. To assess the instrument's reliability, an additional sample comprising 50 patients was subjected to 2 interviews, and the results were assessed using the quadratic weighted kappa value. The instrument's internal consistency was assessed using Cronbach's alpha $(n=105)$, and the standard error of measurement was also calculated $(n=50)$. Results: Translation and back-translation attained consensus, and only item 6 required changes; the reformulated version was applied to an additional sample comprising 52 individuals who did not report any doubts related to this item. The reliability of the SBST-Brazil was 0.79 (95\% confidence interval: $0.63-0.95)$, the internal consistency was 0.74 for the total score and 0.72 for the psychosocial subscale, and the standard error of measurement was $1.9 \%$. Conclusion: The translated and cross-culturally adapted SBST-Brazil proved to be reliable for screening patients according to their risk of poor prognosis and the presence of psychosocial factors.
\end{abstract}

Keywords: low back pain; questionnaire; STarT Back Screening Tool; rehabilitation; reliability.

\section{HOW TO CITE THIS ARTICLE}

Pilz B, Vasconcelos RA, Marcondes FB, Lodovichi SS, Mello WA, Grossi DB. The Brazilian version of STarT Back Screening Tool - translation, cross-cultural adaptation and reliability. Braz J Phys Ther. 2014 Sept-Oct; 18(5):453-461. http://dx.doi. org/10.1590/bjpt-rbf.2014.0028

\section{Introduction}

Low back pain is a major health problem worldwide, affecting mostly females and individuals aged $40-80$ years. Approximately $11.9 \%$ of patients exhibit limitations due to low back pain for more than 1 day, and $23.2 \%$ of patients show limitations for more than 1 month $^{1}$. Most patients with acute low back pain $(90 \%)$ recover within 6 weeks, but symptoms remain in 2 to $7 \%$ of patients. These symptoms progress into chronic pain, which accounts for $75-85 \%$ of absenteeism in the workplace ${ }^{2}$. In addition, $53 \%$ of individuals with chronic low back pain from a specific population exhibit significant psychological disorders ${ }^{3}$.
The emotional and behavioral impact of this pain favors the development of chronic conditions ${ }^{4-6}$, and some evidence shows that psychosocial factors, including the patient's perception about the resolution of the symptoms of low back pain and their association with other diseases, difficulty in coping with the disease, lack of confidence, pain catastrophizing, and depressive symptoms, are predictive of dysfunction and interfere with the prognosis of low back pain ${ }^{7-12}$. Identification in the primary care setting of patients exhibiting psychosocial factors liable to interfere with their prognosis $\mathrm{s}^{2,7,8,13}$ contributes to establishing more specific treatments and allows the patient to

\footnotetext{
${ }^{1}$ Núcleo de Estudos e Pesquisa, Instituto Wilson Mello, Campinas, SP, Brazil

${ }^{2}$ Programa de Pós-graduação em Reabilitação e Desempenho Funcional, Faculdade de Medicina de Ribeirão Preto (FMRP), Universidade de São Paulo (USP), Ribeirão Preto, SP, Brazil

${ }^{3}$ Universidade Estadual de Campinas (UNICAMP), Campinas, SP, Brazil

${ }^{4}$ Centro Universitário da Fundação Educacional de Guaxupé (UNIFEG), Guaxupé, MG, Brazil

Received: 01/28/2014 Revised: 03/25/2014 Accepted: 03/31/2014

*Abstract presented at the IV Meeting Internacional Científico IBRAMED.
} 
better understand the consequences of the signs and symptoms of low back pain ${ }^{13}$. These facts notwithstanding, the influence of psychosocial factors is not fully understood and is poorly considered in the planning of treatment. For these reasons, the identification of such factors still poses a challenge $e^{5,8}$.

Thus, the application of a questionnaire to assess psychosocial factors may enable the stratification of individuals with low back pain and contribute to therapeutic decision-making.

Recently, Hill et al. ${ }^{14}$ formulated the "STarT Back Screening Tool" (SBST) questionnaire. Developed in English, the SBST classifies the risk of poor prognosis of low back pain patients with or without radiculopathy influenced by physical and psychosocial factors. The SBST was shown to be able to predict future dysfunction in patients with low back pain in the primary care setting and exhibited acceptable test-retest reliability and internal consistency ${ }^{15}$.

Several studies have tested the effectiveness of the SBST ${ }^{12,13,15-17}$. Hill et al. ${ }^{18}$ found that patients stratified and treated based on the SBST exhibited better performance on the Rolland-Morris Disability Questionnaire and consequently better quality of life, less use of healthcare services, and lower number of days off work compared to the control group, which was not stratified.

However, there are few questionnaires available in Brazil to assess the risk of poor prognosis among patients with low back pain influenced by physical and psychosocial factors. For this reason, the aims of the present study were to translate and crossculturally adapt the SBST to the Brazilian Portuguese language and to analyze its psychometric properties of reliability through assessment of intra-rater reliability, internal consistency, and standard error of measurement to provide a reliable tool for screening individuals with low back pain. Such a tool will afford physical therapists with a differentiated approach and improve their clinical decision-making skills in both the clinical and research settings.

\section{Method}

\section{Description of the SBST questionnaire}

The SBST questionnaire is comprised of 9 items. Of these, 4 are related to refererred leg pain, disability, and comorbid shoulder or neck pain, and 5 of the items make up a psychosocial subscale (items 5 to 9) that investigates bothersomeness, pain catastrophizing, fear, anxiety, and depression ${ }^{12,14,15,18}$. The SBST-Brazil includes the changes introduced and the order of the items formulated by Fritz et al. ${ }^{12}$ and Hill et al. ${ }^{18}$, which the authors of the original instrument recommended to facilitate patient classification.

Using the SBST in the study, patients were classified as having a high risk of poor prognosis (high levels of psychosocial prognostic factors were present with or without the physical factors present); medium risk (physical and psychosocial factors were present, but not a high level of psychosocial factors); or low risk (few physical or psychosocial prognostic factors were present $)^{12,18}$.

For the purposes of scoring and classification, respondents were given answer options of "I agree" and "I disagree" for the first 8 items, which were scored 1 and 0 points, respectively. Item 9 had 5 answer options, including "Not at all, Slightly, Moderately, Very much, and Extremely"; the first 3 options were assigned 0 points, and the latter 2 were given 1 point each. Total scores from 0-3 corresponded to a low risk. For total scores greater than 3, classification was based on the psychosocial subscale score (items 5 to 9 ) as follows: scores $\leq 3$ corresponded to medium risk and scores $>3$ corresponded to high risk ${ }^{12,14,18}$. Figure 1 depicts the SBST classification system.

\section{Translation and cross-cultural adaptation}

Cross-cultural adaptation of the SBST questionnaire was performed using the methods described by Beaton et al. ${ }^{19}$. Authorization for this process was requested from the author of the original version, Dr. Jonathan Hill, Keele University, United Kingdom. The present study was approved by the Research Ethics Committee of the Pontifical Catholic University of Campinas (Pontifícia Universidade Católica de Campinas - PUC-Campinas), Campinas, São Paulo, Brazil, under ruling no. 150.139.

The modified SBST version ${ }^{12,18}$ was used for cross-cultural adaptation, which was performed in the following 6 steps: (1) translation, (2) synthesis, (3) back-translation, (4) revision by the Translation Group, (5) pretest, and (6) assessment by an expert panel.

First, the SBST, which was originally developed in English, was independently translated into Brazilian Portuguese by 2 bilingual public translators (T1 and T2) who were native Portuguese speakers and fluent in English; only one of these translators had knowledge about health subjects. The resulting translations ( $\mathrm{T} 1$ and $\mathrm{T} 2$ ) were then analyzed together with the original questionnaire by the translators and 
the investigators (second synthesis step), resulting in version $\mathrm{T} 12$.

In the third step, version T12 was back-translated into English by 2 different bilingual translators (BT1 and BT2) who had no knowledge about the original English version of the questionnaire; these translators were native English speakers residing in Brazil and fluent in Brazilian Portuguese.

In the fourth step, all 5 versions (original, T1, T2, T12, BT1, and BT2) were revised by the Translation Group, which comprised one physical therapist, 2 orthopedic doctors, and all 4 translators. The Translation Group consolidated all 5 versions to produce a pre-final version of the SBST questionnaire.

In the fifth step, 2 pretests were performed with the pre-final version to eliminate any item not understood by more than $20 \%$ of the sample ${ }^{20}$. In the sixth step, all of the reports were submitted to the Committee for approval, after which they were sent to the author of the original version to approve the final version.

A convenience sample was recruited at Wilson Mello Institute, Campinas, São Paulo, Brazil. This sample comprised individuals older than 18 years of age with low back pain, independent of the time elapsed since the onset of their back pain and with or without extension of pain to the lower limbs.

Individuals with severe clinical problems (e.g., cauda equina syndrome, fracture of the lumbar spine, malignancy, and cognitive, neurologic, or rheumatologic disorders), those subjected to lumbar spine surgery within the previous 6 months, pregnant women, and those who could not read or speak Brazilian Portuguese were excluded from the study. All patients who agreed to participate in this stage of the study and in the reliability assessment signed an informed consent form and provided demographic information, which is summarized in Table 1. The questionnaire was self-administered, and once the

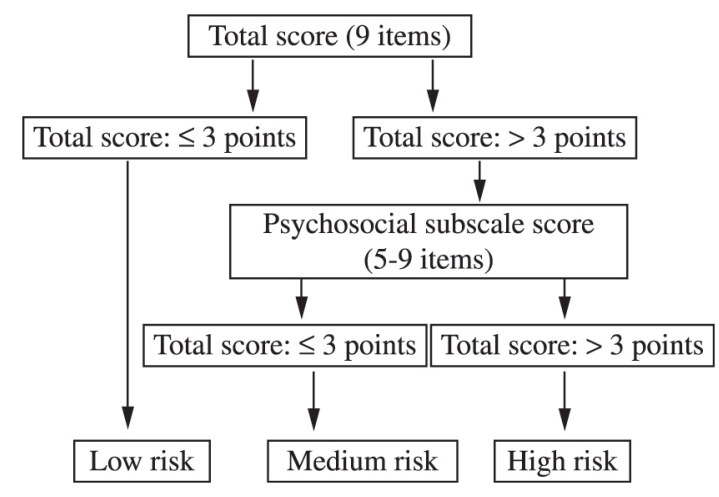

Figure 1. SBST scoring system ${ }^{12,14,18}$. patients answered the pre-final version, they were each questioned by one of the investigators as to their understanding of each item to formulate suggestions for improvement.

\section{Psychometric properties}

\section{Reliability}

All of the properties corresponding to domain reliability were tested, including intra-rater reliability, internal consistency, and standard error of measurement ${ }^{21}$. Inter-rater reliability was not tested because the STBS is a self-administered questionnaire not subjected to any interference by examiners.

\section{Intra-rater reliability}

To assess the intra-rater reliability of the SBSTBrazil questionnaire, a different sample comprising 50 patients with unspecific low back pain was subjected to 2 interviews, as recommended by the Consensus-based Standards for the Selection of Health Measurement Instruments (COSMIN) ${ }^{21}$. The patients were recruited by means of convenience sampling at the physical therapy service of the Wilson Mello Institute, Campinas, São Paulo, Brazil.

The 2 interviews were conducted with an interval of 2 to 7 days, depending on the availability of the patients, and the SBST-Brazil questionnaire and a numerical rating scale (NRS) for pain ${ }^{22}$ were applied to all subjects. The NRS scale was used only as an exclusion tool. Only stable patients (i.e., those whose NRS scores exhibited variation of 2 points or less between both assessments) were considered for the study, because this value was considered as the minimal clinically important difference (MCID) for patients with chronic low back pain ${ }^{23}$. Patients with variations in the NRS score greater than 2 points and those who missed the second interview were excluded from the study.

\section{Internal consistency}

A pilot study was conducted in which the SBSTBrazil questionnaire was applied to 105 patients with low back pain to test its internal consistency using Cronbach's alpha. The initial results, showing a value of 0.59 in the total score and 0.51 in the psychosocial scale, were considered unacceptable ${ }^{21}$. Analysis of the characteristics of the sample showed wide heterogeneity relative to the variables educational level ( $9 \%$ had completed primary education only, $20 \%$ secondary education, and $71 \%$ had completed 
Table 1. Demographic characteristics and SBST-Brazil results of the subjects involved in the study at baseline.

\begin{tabular}{|c|c|c|c|c|}
\hline Demographics variables & $\begin{array}{l}\text { Pre-final version I } \\
(\mathrm{n}=52)\end{array}$ & $\begin{array}{c}\text { Pre-final version II } \\
(\mathrm{n}=52)\end{array}$ & $\begin{array}{c}\text { Intra-rater reliability } \\
\text { SEM }(\mathbf{n}=\mathbf{5 0})\end{array}$ & $\begin{array}{l}\text { Internal Consistency } \\
(\mathrm{n}=105)\end{array}$ \\
\hline Age (years), mean (SD) & $48.87(16.1)$ & $50.1(19.3)$ & $48(14.5)$ & $47.8(14.2)$ \\
\hline \multicolumn{5}{|l|}{ Gender, n (\%) } \\
\hline Male & $18(34 \%)$ & $24(46 \%)$ & $23(46 \%)$ & $55(52 \%)$ \\
\hline Female & $34(66 \%)$ & $28(54 \%)$ & $27(54 \%)$ & $50(48 \%)$ \\
\hline BMI, mean (SD) & & & $25.35(3.6)$ & $26.3(4.5)$ \\
\hline \multicolumn{5}{|l|}{ Education, n (\%) } \\
\hline Primary education level & $17(32.6 \%)$ & $16(30.7 \%)$ & $0(0 \%)$ & $26(24.7 \%)$ \\
\hline High school level & $33(63.4 \%)$ & $31(59.6 \%)$ & $15(30 \%)$ & $46(43.8 \%)$ \\
\hline University level & $2(4 \%)$ & $5(9.7 \%)$ & $35(70 \%)$ & $33(31.5 \%)$ \\
\hline NRS, mean (SD) & & & $5.6(1.9)$ & $5.5(2.2)$ \\
\hline SBST- Brazil, mean (SD) & & & $2.64(2.16)$ & $4.1(2.2)$ \\
\hline Low risk, n (\%) & & & $26(52 \%)$ & $53(50 \%)$ \\
\hline Medium risk, n (\%) & & & $17(34 \%)$ & $28(26 \%)$ \\
\hline High risk, n (\%) & & & $7(14 \%)$ & $24(24 \%)$ \\
\hline
\end{tabular}

BMI: body mass index; NRS: numeric rating scale; SEM: standard error measurement; SD: standard deviation.

higher education) and risk stratification based on the SBST (40\% were classified as low risk, $43 \%$ as medium risk, and $17 \%$ as high risk). Thus, a new sample $(\mathrm{n}=105)$ more homogeneous in regard to educational level (primary education: $24.7 \%$; secondary education: $43.8 \%$; complete higher education: $31.5 \%$ ) and risk stratification (low risk: 50\%; medium risk: 26\%; high risk: $24 \%$ ) was recruited to test the internal consistency of the SBSTBrazil questionnaire.

\section{Standard Error of Measurement (SEM)}

The SEM was calculated based on data corresponding to the sample that participated in the first interview for reliability analysis. The SEM does not represent actual changes in the questionnaire results but instead error in measurement ${ }^{24}$.

\section{Statistical analysis}

Intra-rater reliability was assessed using the quadratic weighted kappa coefficient with the corresponding $95 \%$ confidence interval (CI). Following the methods of Sim and Wright ${ }^{25}$, reliability values were classified as poor $(\leq 0)$, slight (0.01-0.2), fair (0.21-0.40), moderate (0.41-0.60), substantial (0.61-0.80), and almost perfect (0.81-1.0). Values equal to or higher than 0.70 were expected to be found for the reliability of the SBST, according to COSMIN recommendations ${ }^{21}$. Analysis was performed using the software SAS (version 9.2).
The data relative to internal consistency were tested using Cronbach's alpha, with values within the 0.70-0.95 range considered acceptable ${ }^{24}$.

SEM was calculated according to the equation $\mathrm{SEM}_{95}=1.96 * \mathrm{SD} * \sqrt{ }\left(1-\mathrm{Kappa}_{\text {test-retest }}\right)$ with the corresponding $95 \% \mathrm{CI}^{26}$. Results equal to or lower than $5 \%$ were considered very good; 5.1 to $10 \%$ as good; 10.1 to $20 \%$ as questionable; and above $20.1 \%$ as poor $^{27}$.

\section{Results}

The demographic characteristics of the patients involved in the various steps of the study are described in Table 1.

\section{Cross-cultural adaptation}

Initial cross-cultural adaptation of the SBST questionnaire to Brazilian Portuguese resulted in similar versions, with translations $\mathrm{T} 1$ and $\mathrm{T} 2$ exhibiting small differences. Table 2 shows how these differences were solved. As a result, the first and second steps of the process were completed, resulting in version $\mathrm{T} 12$.

Analysis of the back-translations showed that versions $\mathrm{BT} 1$ and $\mathrm{BT} 2$ were quite similar and equivalent to the original version of the SBST questionnaire, thus indicating that version T12 was adequate to obtain the pre-final version. 
The first pretest indicated that only item 6 of the questionnaire required changes, as the statement "Tenho ficado preocupado por muito tempo [Worrying thoughts have been going through my mind a lot of the time]" was not understood by more than $20 \%$ of the participants ${ }^{20}$. Following revision by the Translation Group and complying with a suggestion made by the author of the SBST, the text of item 6 was changed to "Tenho ficado preocupado por muito tempo por causa da minha dor nas costas [Worrying thoughts have been going through my mind a lot of the time due to the pain in my back]". Following this change, the patients did not report any doubts on the second pretest, and thus the final Brazilian Portuguese version of the SBST was established, which is presented in Appendix 1.

\section{Reliability}

The intra-rater reliability was considered to be substantial ${ }^{25}$ according to the reference values selected, as the result was greater than 0.70 , which is the established minimum ${ }^{21}$.

The internal consistency values of the SBST-Brazil questionnaire were also acceptable (total score: 0.74; psychosocial subscale: 0.72 ), and the SEM was rated very good. These results are described in Table 3.

\section{Discussion}

Reliable application of foreign questionnaires to the Brazilian population demands their systematic and judicious cross-cultural adaptation to the Brazilian Portuguese language. Cross-cultural adaptation of specific questionnaires is not simple, as not only language-related but also cultural differences between countries should be taken into consideration for the validity and reliability of instruments to be preserved $^{19,26}$. For these reasons, the cross-cultural adaptation of the SBST questionnaire was performed with utmost care relative to the semantic, idiomatic, and conceptual equivalence, while preserving the original concepts ${ }^{28}$. Only item 6 posed doubts to the patients, and changes in its text were suggested by the original author of the SBST to conserve its intention. As a result, the new text was approved by the expert panel, and retest using a different sample showed that this item no longer posed doubts regarding its meaning.

The SBST-Brazil is the first Brazilian questionnaire designed to screen and classify patients with low back pain as to their risk of poor prognosis relative to physical therapy due to psychosocial factors. Although the original version of the SBST was translated to other languages, including Spanish, French, Danish, Arabic, Dutch, German, Italian,

Table 2. SBST- Brazil questionnaire translation process modification.

\begin{tabular}{|c|c|c|c|c|}
\hline ITEM & Original Version & T 1 & T 2 & T 12 \\
\hline 3 & $\begin{array}{l}\text { I have only walked short } \\
\text { distances }\end{array}$ & $\begin{array}{l}\text { Evito andar longas } \\
\text { distâncias }\end{array}$ & $\begin{array}{l}\text { Eu somente andei curtas } \\
\text { distâncias }\end{array}$ & $\begin{array}{l}\text { Eu evito andar longas } \\
\text { distâncias }\end{array}$ \\
\hline 4 & $\begin{array}{l}\text { I have dressed more } \\
\text { slowly than usual }\end{array}$ & Demora para eu me vestir & $\begin{array}{l}\text { Tenho me vestido mais } \\
\text { lentamente que o habitual }\end{array}$ & $\begin{array}{l}\text { Tenho me vestido mais } \\
\text { devagar }\end{array}$ \\
\hline 5 & $\begin{array}{l}\text { It's really not safe for a } \\
\text { person with a condition } \\
\text { like mine to be physically } \\
\text { active }\end{array}$ & $\begin{array}{l}\text { A atividade física é } \\
\text { perigosa para as pessoas } \\
\text { com a minha doença }\end{array}$ & $\begin{array}{l}\text { Não é realmente seguro } \\
\text { para uma pessoa com uma } \\
\text { condição como a minha } \\
\text { para ser fisicamente ativo }\end{array}$ & $\begin{array}{l}\text { A atividade física não é } \\
\text { realmente segura para } \\
\text { uma pessoa com um } \\
\text { problema como o meu }\end{array}$ \\
\hline 6 & $\begin{array}{l}\text { Worrying thoughts have } \\
\text { been going through my } \\
\text { mind often }\end{array}$ & $\begin{array}{l}\text { Fico preocupado } \\
\text { frequentemente }\end{array}$ & $\begin{array}{l}\text { Pensamentos } \\
\text { preocupantes têm } \\
\text { passando na minha mente }\end{array}$ & $\begin{array}{l}\text { Tenho ficado preocupado } \\
\text { por muito tempo }\end{array}$ \\
\hline
\end{tabular}

Table 3. Intra-rater reliability $(\mathrm{n}=50)$, internal consistency $(\mathrm{n}=105)$ and SEM $(\mathrm{n}=50)$ results for the SBST-Brazil questionnaire.

\begin{tabular}{|c|c|c|c|}
\hline & $\begin{array}{c}\text { Classification } \\
\text { Low/ Medium/High } \\
\text { risk }(95 \% \mathrm{CI})\end{array}$ & Total Score & Psychosocial Subscale Score \\
\hline $\begin{array}{l}\text { Intra-rater reliability (Quadratic } \\
\text { weighted kappa) }\end{array}$ & $0.79(0.63-0.95)$ & & \\
\hline Internal consistency & & 0.74 & 0.72 \\
\hline SEM (\%) & & 1.9 & \\
\hline
\end{tabular}

SEM: Standard error measurement. 
Polish, Norwegian, Mandarin, Japanese, Swedish, Turkish, Urdu, Welsh, and Yoruba ${ }^{29}$, no adaptation to Brazilian Portuguese was available.

In our analysis, the quadratic weighted kappa value was 0.79 (95\% CI: 0.63-0.95), which indicates that the intra-rater reliability of the SBST-Brazil was acceptable relative to the classification result and close to the value of the original version ${ }^{14}$, which are 0.73 (95\% CI: $0.57-0.84$ ) for the total score and 0.76 (95\% CI: 0.52-0.89) for the psychosocial subscale.

The internal consistency results were greater than 0.70 (total score: 0.74 ; psychosocial subscale: 0.72 ) and these values are similar to those corresponding to the SBST original ${ }^{14}$ (total score: 0.79 ; psychosocial subscale: 0.74 ), French ${ }^{30}$ (psychosocial subscale: 0.74 ), and $\operatorname{Iranian}^{31}$ (total score: 0.82 ; psychosocial subscale: 0.79 ) versions, all of which are recommended for use in clinical and research settings. To date, only internal consistency values for the latter 2 versions have been reported, and the samples used in those versions did not comprise as broad a scope of clinical conditions as that in the present study. Indeed, the Brazilian version of the SBST achieved acceptable values using a sample comprising patients with a broad scope of clinical conditions, including unspecific low back pain and postoperative low back pain, with or without arthrodesis, spondylolisthesis, foraminal stenosis, and degenerative central canal stenosis, and thus was representative of the realworld physical therapy setting. Despite the wide variety of clinical conditions, the sample used in the present study exhibited homogeneous distribution as to the patients' educational level and risk stratification. In comparison, the sample used in the pilot study previously conducted to test the internal consistency of the SBST-Brazil included a low percentage of patients with low educational levels and those classified as high risk, and the resulting internal consistency was less than 0.70 (total score: 0.59; psychosocial subscale: 0.51 ). However, this sample achieved greater representativeness after the variables risk level and educational level were more homogeneously distributed. As a result, the final SBST-Brazil demonstrated satisfactory internal consistency for use in patients with various clinical low back pain conditions.

In regard to the internal consistency of the SBST-Brazil, it is worth noting that this instrument focuses on the assessment of psychosocial aspects related to coping that can be strongly influenced by the psychosocial profile of the sample. Therefore, future studies will also be able to establish whether the internal consistency values of the SBST-Brazil remain acceptable in individuals corresponding to the same clinical, diagnostic, or sociocultural strata.

The SEM calculated for the SBST-Brazil was classified as very good ${ }^{27}$. This result also indicates that the actual score of any individual may vary $1.9 \%$ above or below the score attained in the applied questionnaire, which is not indicative of any real change in the patient's clinical condition but merely reflects an error in measurement.

The reliability domain exhibited satisfactory results that were quite similar to those corresponding to the original version of the questionnaire, indicating that the SBST-Brazil is reliable for application to the Brazilian population.

Use of the SBST can lead to significant differences in the standard treatment provided to different groups of individuals with low back pain in the primary care setting ${ }^{18}$. Patients classified as high risk using this instrument exhibit unfavorable prognosis due to the presence of psychosocial factors, and may not have access to specif treatment what includes physical and psychosocial components based on cognitive and behavioral principles, and thus could not exhibit satisfactory outcomes. Although the prognosis of patients classified as medium risk is less unfavorable compared to those classified as high risk, these subjects also require physical therapy, mainly because of their physical symptoms. The prognosis of individuals classified as low risk is good, and they may benefit from advice and explanation about their symptoms, reassurance, education about their daily and work activities, with no need for physical therapy on a steady basis. The abovementioned features show that the SBST allows physical therapists to define more accurately the best approach to treatment for each individual patient.

Upon comparing subjective decision-making by clinical experts to the SBST's allocation to risk subgroups, Hill et al. ${ }^{17}$ found that the agreement between the group assessed by clinicians and the group assessed using the SBST was poor. In addition, the results of the latter group were better than those of the former, which is indicative of the difficulties clinicians encounterin identifying individuals at high risk of poor prognosis. The SBST aids in the identification of individuals who require special care and thus represents an important adjuvant to clinical assessment.

Nevertheless, the SBST has some limitations, including the failure to identify psychosocial problems in individuals without pain complaints and the inability to specify the patient's preferences, expectations, and past treatments ${ }^{17}$. The usefulness of 
the SBST for screening patients with low back pain notwithstanding, other questionnaires should be used during clinical follow up, such as the Fear-Avoidance Beliefs Questionnaire (FABQ) or the shortened version of the Tampa Scale for Kinesiophobia $\left(\right.$ TKS-11) ${ }^{15}$.

The SBST can contribute to the initial screening of individuals with low back pain to improve their treatment, as well as to the performance of clinical studies of individuals with low back pain. In addition, based on the present study, other psychometric properties of the SBST may also be assessed.

\section{Conclusion}

The translation and cross-cultural adaptation of the SBST to the Brazilian Portuguese language was performed in a satisfactory manner. The resulting SBST-Brazil version proved to be reliable for use in Brazil, thus contributing to the treatment of individuals with low back pain in the primary care setting by screening them for a risk of poor prognosis and taking psychosocial factors into account.

\section{References}

1. Hoy D, Bain C, Williams G, March L, Brooks P, Blyth $\mathrm{F}$, et al. A systematic review of the global prevalence of low back pain. Arthritis Rheum. 2012;64(6):2028-37. http:// dx.doi.org/10.1002/art.34347. PMid:22231424

2. van Tulder M, Becker A, Bekkering T, Breen A, del Real MT, Hutchinson A, et al. Chapter 3. European guidelines for the management of acute nonspecific low back pain in primary care. Eur Spine J. 2006;15(S2, Suppl 2):S169-91. http:// dx.doi.org/10.1007/s00586-006-1071-2. PMid:16550447

3. Apeldoorn AT, Bosselaar H, Ostelo RW, Blom-Luberti T, van der Ploeg T, Fritz JM, et al. Identification of patients with chronic low back pain who might benefit from additional psychological assessment. Clin J Pain. 2012;28(1):2331. http://dx.doi.org/10.1097/AJP.0b013e31822019d0. PMid:21677570

4. Nicholas MK. Depression in people with pain: There is still work to do. Commentary on 'Understanding the link between depression and pain'. Scandinavian Journal of Pain. 2011;2(2):45-6. http://dx.doi.org/10.1016/j. sjpain.2011.02.003.

5. Linton SJ, Shaw WS. Impact of psychological factors in the experience of pain. Phys Ther. 2011;91(5):700-11. http:// dx.doi.org/10.2522/ptj.20100330. PMid:21451097

6. Nicholas MK. Mental disorders in people with chronic pain: an international perspective. Pain. 2007;129(3):231-2. http:// dx.doi.org/10.1016/j.pain.2007.03.011. PMid:17451878

7. Airaksinen O, Brox JI, Cedraschi C, Hildebrandt J, KlaberMoffett J, Kovacs F, et al. Chapter 4. European guidelines for the management of chronic nonspecific low back pain.
Eur Spine J. 2006;15(S2, Supp1 2):S192-300. http://dx.doi. org/10.1007/s00586-006-1072-1. PMid:16550448

8. Nicholas MK, Linton SJ, Watson PJ, Main CJ, and the "Decade of the Flags" Working Group. Early identification and management of psychological risk factors ("yellow flags") in patients with low back pain: a reappraisal. Phys Ther. 2011;91(5):737-53. http://dx.doi.org/10.2522/ ptj.20100224. PMid:21451099

9. Pincus T, Burton AK, Vogel S, Field AP. A systematic review of psychological factors as predictors of chronicity/ disability in prospective cohorts of low back pain. Spine (Phila Pa 1976). 2002;27(5):E109-20. http://dx.doi. org/10.1097/00007632-200203010-00017. PMid:11880847

10. Hill JC, Fritz JM. Psychosocial influences on low back pain, disability, and response to treatment. Phys Ther. 2011;91(5):712-21. http://dx.doi.org/10.2522/ptj.20100280. PMid:21451093

11. Foster NE, Thomas E, Bishop A, Dunn KM, Main CJ. Distinctiveness of psychological obstacles to recovery in low back pain patients in primary care. Pain. 2010;148(3):398-406. http://dx.doi.org/10.1016/j. pain.2009.11.002. PMid:20022697

12. Fritz JM, Beneciuk JM, George SZ. Relationship between categorization with the STarT Back Screening Tool and prognosis for people receiving physical therapy for low back pain. Phys Ther. 2011;91(5):722-32. http://dx.doi. org/10.2522/ptj.20100109. PMid:21451094

13. Main CJ, Sowden G, Hill JC, Watson PJ, Hay EM. Integrating physical and psychological approaches to treatment in low back pain: the development and content of the STarT Back trial's 'high-risk' intervention (StarT Back; ISRCTN 37113406). Physiotherapy. 2012;98(2):110-6. http://dx.doi. org/10.1016/j.physio.2011.03.003. PMid:22507360

14. Hill JC, Dunn KM, Lewis M, Mullis R, Main CJ, Foster $\mathrm{NE}$, et al. A primary care back pain screening tool: identifying patient subgroups for initial treatment. Arthritis Rheum. 2008;59(5):632-41. http://dx.doi.org/10.1002/ art.23563. PMid:18438893

15. Beneciuk JM, Bishop MD, Fritz JM, Robinson ME, Asal NR, Nisenzon AN, et al. The STarT back screening tool and individual psychological measures: evaluation of prognostic capabilities for low back pain clinical outcomes in outpatient physical therapy settings. Phys Ther. 2013;93(3):321-33. http://dx.doi.org/10.2522/ptj.20120207. PMid:23125279

16. Wideman TH, Hill JC, Main CJ, Lewis M, Sullivan MJL, Hay EM. Comparing the responsiveness of a brief, multidimensional risk screening tool for back pain to its unidimensional reference standards: the whole is greater than the sum of its parts. Pain. 2012;153(11):2182-91. http:// dx.doi.org/10.1016/j.pain.2012.06.010. PMid:22800410

17. Hill JC, Vohora K, Dunn KM, Main CJ, Hay EM. Comparing the STarT back screening tool's subgroup allocation of individual patients with that of independent clinical experts. Clin J Pain. 2010;26(9):783-7. http://dx.doi. org/10.1097/AJP.0b013e3181f18aac. PMid:20842014

18. Hill JC, Whitehurst DGT, Lewis M, Bryan S, Dunn KM, Foster NE, et al. Comparison of stratified primary care management for low back pain with current best practice (STarT Back): a randomised controlled trial. Lancet. 
2011;378(9802):1560-71. http://dx.doi.org/10.1016/S01406736(11)60937-9. PMid:21963002

19. Beaton DE, Bombardier C, Guillemin F, Ferraz MB. Guidelines for the process of cross-cultural adaptation of self-report measures. Spine (Phila Pa 1976). 2000;25(24):3186-91. http://dx.doi.org/10.1097/00007632200012150-00014. PMid:11124735

20. Nusbaum L, Natour J, Ferraz MB, Goldenberg J. Translation, adaptation and validation of the RolandMorris questionnaire-Brazil Roland-Morris. Braz J Med Biol Res. 2001;34(2):203-10. http://dx.doi.org/10.1590/ S0100-879X2001000200007. PMid:11175495

21. Mokkink LB, Terwee CB, Patrick DL, Alonso J, Stratford PW, Knol DL, et al. The COSMIN study reached international consensus on taxonomy, terminology, and definitions of measurement properties for health-related patient-reported outcomes. J Clin Epidemiol. 2010;63(7):737-45. http:// dx.doi.org/10.1016/j.jclinepi.2010.02.006. PMid:20494804

22. Salaffi F, Sarzi-Puttini P, Ciapetti A, Atzeni F. Clinimetric evaluations of patients with chronic widespread pain. Best Pract Res Clin Rheumatol. 2011;25(2):249-70. http://dx.doi. org/10.1016/j.berh.2011.01.004. PMid:22094200

23. Lauridsen HH, Hartvigsen J, Manniche C, Korsholm L, Grunnet-Nilsson N. Responsiveness and minimal clinically important difference for pain and disability instruments in low back pain patients. BMC Musculoskelet Disord. 2006;7(1):82. http://dx.doi.org/10.1186/1471-2474-7-82. PMid: 17064410

24. Terwee CB, Bot SDM, de Boer MR, van der Windt DA, Knol DL, Dekker J, et al. Quality criteria were proposed for measurement properties of health status questionnaires. J Clin Epidemiol. 2007;60(1):34-42. http:// dx.doi.org/10.1016/j.jclinepi.2006.03.012. PMid:17161752

25. Sim J, Wright CC. The kappa statistic in reliability studies: use, interpretation, and sample size requirements. Phys Ther. 2005;85(3):257-68. PMid:15733050.

26. Beaton DE. Understanding the relevance of measured change through studies of responsiveness. Spine.
2000;25(24):3192-9. http://dx.doi.org/10.1097/00007632200012150-00015. PMid:11124736

27. Magalhães MO, Costa LO, Ferreira ML, Machado LA. Clinimetric testing of two instruments that measure attitudes and beliefs of health care providers about chronic low back pain.. Rev Bras Fisioter. 2011;15(3):249-56. http://dx.doi.org/10.1590/S1413-35552011000300012. PMid:21829990

28. Marcondes FB, Vasconcelos RA, Marchetto A, Andrade ALL, Zoppi Filho A, Etchebehere M. Tradução e adaptação cultural do Rowe Score para a língua portuguesa. Acta Ortop Bras. 2012;20(6):346-50. http://dx.doi.org/10.1590/ S1413-78522012000600007. PMid:24453630

29. Keele.ac.uk. North Staffordshire: The STarT Back Screening tool website [Internet]. 2013 [cited 2014 March 27]. Available from: http://www.keele.ac.uk/sbst/ translatedversions/.

30. Bruyère $\mathrm{O}$, Demoulin $\mathrm{M}$, Beaudart $\mathrm{C}$, Hill JC, Maquet $\mathrm{D}$, Genevay S, et al. Validity and reliability of the French Version of the STarT back screening tool for patients with low back pain. Spine (Phila Pa 1976). 2014;39(2):E1238. http://dx.doi.org/10.1097/BRS.0000000000000062. PMid:24108286

31. Azimi P, Shahzadi S, Azhari S, Montazeri A. A validation study of the Iranian version of STarT Back Screening Tool (SBST) in lumbar central canal stenosis patients. J Orthop Sci. 2014;19(2):213-7. http://dx.doi.org/10.1007/ s00776-013-0506-y. PMid:24343300

\section{Correspondence \\ Bruna Pilz}

Instituto Wilson Mello, Fisioterapia

Rua José Rocha Bonfim, 214, Ed. Chicago, $1^{\circ}$ andar,

Condomínio Praça Capital, Santa Genebra

CEP 13080-650, Campinas, SP, Brasil

e-mail: bruna@iwmello.com.br 


\section{Appendix 1. STarT Back Screening Tool- Brasil (SBST-Brasil).}

Pensando nas duas últimas semanas, assinale sua resposta para as seguintes perguntas:

Discordo (0) Concordo (1)

1. A minha dor nas costas se espalhou pelas pernas nas duas últimas semanas

( )

2. Eu tive dor no ombro e/ou na nuca pelo menos uma vez nas últimas duas semanas

3. Eu evito andar longas distâncias por causa da minha dor nas costas

4. Nas duas últimas semanas, tenho me vestido mais devagar por causa da minha dor nas costas

5. A atividade física não é realmente segura para uma pessoa com um problema como o meu

6. Tenho ficado preocupado por muito tempo por causa da minha dor nas costas

7. Eu sinto que minha dor nas costas é terrível e que nunca vai melhorar

8. Em geral, eu não tenho gostado de todas as coisas como eu costumava gostar

9. Em geral, quanto a sua dor nas costas te incomodou nas duas ultimas semanas ( ) Nada (0) ( ) Pouco (0) ( ) Moderado (0) ( ) Muito(1) ( ) Extremamente(1)

Pontuação total (9 itens): Subescala psicossocial (5-9 itens): 